Fortschritt-Berichte VDl

VDI

Reihe 17

Biotechnik/

Medizintechnik

Nr. 296
M. Sc. Ben Nikolas Bufe,

Duisburg

Method for Non-Invasive

Skin Artifact-Free

Spatial Bone Motion

Tracking Using Pressure

Sensor Foils 


\section{Method for Non-Invasive Skin Artifact-Free Spatial Bone Motion Tracking Using Pressure Sensor Foils}

Der Fakultät für Ingenieurwissenschaften, Abteilung Maschinenbau und

Verfahrenstechnik der

Universität Duisburg-Essen

zur Erlangung des akademischen Grades

eines

Doktors der Ingenieurwissenschaften

Dr.-Ing.

genehmigte Dissertation

von

Ben Nikolas Bufe

aus

Hamburg, Deutschland

Referent: Prof. Dr.-Ing. Andrés Kecskeméthy

Korreferent: Prof. Janet Lenore Ronsky, PhD., P.Eng., FCAE

Tag der mündlichen Prüfung: 12. Juli 2019 


\section{Fortschritt-Berichte VDI}

Reihe 17

Biotechnik/

Medizintechnik

Nr. 296
M. Sc. Ben Nikolas Bufe, Duisburg

Method for Non-Invasive

Skin Artifact-Free

Spatial Bone Motion

Tracking Using Pressure

Sensor Foils

\section{VDI verlag}




\title{
Bufe, Ben Nikolas \\ Method for Non-Invasive Skin Artifact-Free Spatial Bone Motion Tracking Using Pressure Sensor Foils
}

Fortschr-Ber. VDI Reihe 17 Nr. 296. Düsseldorf: VDI Verlag 2019.

92 Seiten, 53 Bilder, 15 Tabellen.

ISBN 978-3-18-329617-0, ISSN 0178-9600,

€ 38,00/VDI-Mitgliederpreis € 34,50.

Keywords: In-vivo bone motion tracking - Non-invasive - Skin artifact-free - Radiation-free point-model approximation - Pressure-foil palpation - Three-Ellipsoid 2D-3D registration - Pressure point identification

This work addresses the development of a novel method for bone pose estimation that is both, non-invasive and accurate. The main principal is to palpate three prominent bone protuberances using pressure sensor planes attached to the skin. Bone protuberances are approximated by three ellipsoids that are rigidly attached together. The general formulation of the constraint equations is presented and, as a solution approach, an optimization cost function is proposed allowing bone pose tracking that is insensitive toward input errors. The method is validated invivo using dual fluoroscopy yielding bone tracking precisions in the submillimeter range and below 1 degree, thus, reaching the same order of magnitude as state of the art model based tracking techniques. Finally, the general approach is extended to automatically approximate the rigid body bone geometry via pressure sensor palpation that allows to fully circumvent radiation exposure, making this approach universally applicable.

\section{Bibliographische Information der Deutschen Bibliothek}

Die Deutsche Bibliothek verzeichnet diese Publikation in der Deutschen Nationalbibliographie; detaillierte bibliographische Daten sind im Internet unter www.dnb.de abrufbar.

\section{Bibliographic information published by the Deutsche Bibliothek}

(German National Library)

The Deutsche Bibliothek lists this publication in the Deutsche Nationalbibliographie (German National Bibliography); detailed bibliographic data is available via Internet at www.dnb.de.

\author{
Von der Fakultät für Ingenieurwissenschaften, \\ Abteilung Maschinenbau \\ der Universität Duisburg-Essen \\ genehmigte Dissertation \\ Referent: Prof. Dr.-Ing. Andrés Kecskeméthy \\ Korreferent: Prof. Janet Lenore Ronsky, PhD., P.Eng., FCAE \\ Datum der mündlichen Prüfung: 12. Juli 2019
}

(C) VDI Verlag GmbH . Düsseldorf 2019

Alle Rechte, auch das des auszugsweisen Nachdruckes, der auszugsweisen oder vollständigen Wiedergabe (Fotokopie, Mikrokopie), der Speicherung in Datenverarbeitungsanlagen, im Internet und das der Übersetzung, vorbehalten.

Als Manuskript gedruckt. Printed in Germany.

ISSN 0178-9600

ISBN 978-3-18-329617-0 


\section{Preface}

\section{List of publications}

The present thesis was developed as research associate at the Institute of Mechanics and Robotics ("Lehrstuhl für Mechanik und Robotik") at the University of DuisburgEssen. Many of the contributions and concepts presented in this work were previously published in the following conference publication and proceedings:

- N. Bufe, and A. Kecskeméthy. Position analysis of a planar rigid-body tracked by three ellipse pressure points along straight lines. In Proceedings of the 14 th World Congress in Mechanism and Machine Science, pages 474-482, Taipei, Taiwan, October 25-30 2015.

- N. Bufe, A. Heinemann, P. Köhler, and A. Kecskeméthy. An approach for bone pose estimation via three external ellipsoid pressure points. In 15 th Int. Symposium on Advances in Robot Kinematics, Grasse, France, June 27-30 2016.

- N. Bufe, G. Kuntze, J. L. Ronsky, and A. Kecskeméthy. Fluoroscopy Validation of Noninvasive 3D Bone-Pose tracking via External Pressure-Foils. In Proceedings of the ARK 2018 16th International Symposium on Advances in Robot Kinematics, pages 466-473, Bologna, Italy, July 1-5 2018.

\section{Acknowledgment}

First of all, I would like to thank my supervisor Prof. Andrés Kecskeméthy for supporting me throughout my doctoral thesis. I am very grateful that you gave me the opportunity for all the formative discussions that sharpened my critical thinking and that gave me insight into the world of science. I hope that some of your methodical thinking, your skill of dividing a complex problem into its smallest subproblems, and your mastery of communicating research through text and illustrations will remain with me.

The completion of this thesis would not have been possible without our cooperation partners in Canada. First and foremost, I want to thank Prof. Janet Lenore Ronsky for opening the doors to her lab at the University of Calgary. Without her expertise and openness toward this project, the validation of the methods presented that have shaped 
this thesis would have been impossible. I would also like to thank her working group, in particular Gregor Kuntze, Payam Zandiyeh, Jessica Küpper and Alonso Figueroa for their valuable contributions and technical assistance. Special thanks go to Sarah Sanni and her family for their incredible hospitality making the stay comfortable and enjoyable.

It has been a privilege to work with many great colleagues that allow for thoughtprovoking discussions on every aspect of science and life. Not to mention our unforgettable foosball matches after lunch, providing the necessary balance to work.

I also greatly acknowledge the work of my bachelor students I have had the pleasure to work with: Haoming Zhang, Wen Yang, Shenzhi Yang, Oliver Born, Bingxin Shu, Moxi Liang who made meaningful contributions to this thesis.

Finally, I could not be more fortunate to have a family that has always given me unconditional love and support. Without you, I would not be where I am today!

Duisburg, April 2019

Nikolas Bufe 


\section{Contents}

1 Introduction 1

1.1 Motivation ........................... 1

1.2 State of the art . . . . . . . . . . . . . . . 4

1.2.1 Invasive Procedures . . . . . . . . . . . . . . . . . 4

1.2.2 Non-invasive Procedures . . . . . . . . . . . . . . . . 6

1.3 Objective and overview . . . . . . . . . . . . . . . . . . 7

2 Geometrical problem analysis for the planar case $\quad 9$

2.12 D model description . . . . . . . . . . . . . . . . . . . . 9

2.2 Formulation of the constraint equations . . . . . . . . . . . . . . . . 11

2.3 Characteristics of a symmetric configuration . . . . . . . . . . . . 13

2.4 Determination of the solution variety using Gröbner bases . . . . . . . 14

2.4 .1 Gröbner bases . . . . . . . . . . . . . . . . 14

2.4 .2 Application examples . . . . . . . . . . . . . . . . . . . . . . 15

2.4.3 Sensitivity analysis . . . . . . . . . . . . . . . . 19

2.4.4 Reduction of the solution variety . . . . . . . . . 19

3 3D pose estimation based on the ellipsoid-approximated bone model 23

3.1 Formulation of the constraint equations . . . . . . . . . . . . 23

3.2 Optimization problem ........................ 25

3.3 Sensitivity analysis . . . . . . . . . . . . . . . . 25

4 Self-adjusting point for bone pose estimation 28

4.1 Three-point model description . . . . . . . . . . . . . . . . . . . . . 28 
4.2 Self-adjusting parameter approximation . . . . . . . . . . . . . . . . . . 29

4.3 Approximation-error expectation . . . . . . . . . . . . . . . 30

5 Validations $\quad 32$

5.1 Pressure mapping . . . . . . . . . . . . . . . . . . . . . . . . 32

5.1 .1 Materials and Methods . . . . . . . . . . . . . . 32

5.1 .2 Results........................ 36

5.1 .3 Discussion . . . . . . . . . . . . . . . . 36

5.2 Ellipsoid-approximated bone model validation . . . . . . . . . . . . . 37

5.2.1 Materials and Methods . . . . . . . . . . . . . 37

5.2 .2 Results without initial guess . . . . . . . . . . . . . . . 45

5.2 .3 Results with initial guess . . . . . . . . . . . . . . . . . 47

5.2 .4 Discussion . . . . . . . . . . . . . . . . . . . . 48

5.3 Influence factors of manual 2D-3D registration . . . . . . . . . . 52

5.4 Point-approximated bone model validation . . . . . . . . . . . . . . 52

5.4 Materials and Methods . . . . . . . . . . . . . 52

5.4 .2 Results....................... . . 53

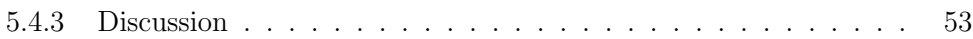

6 Conclusions and outlook $\quad 59$

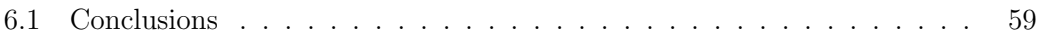

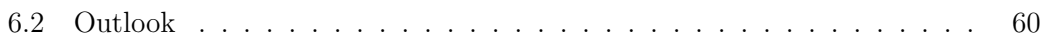

$\begin{array}{ll}\text { Appendices } & 61\end{array}$

A Geometrical problem analysis for the planar case $\quad 62$ 
A.1 General solutions . . . . . . . . . . . . . . . . . . . 62

B 3D pose estimation based on the ellipsoid-approximated bone model 65

B.1 Reference pose for sensitivity analysis . . . . . . . . . . . . 65

$\begin{array}{lc}\text { C Validation } & 66\end{array}$

C.1 Calibration Pencil . . . . . . . . . . . . . . . . . 66

C.2 Residuals - ellipsoid-approximated bone model . . . . . . . . . . . . 67

C.3 Residuals - point-approximated bone model . . . . . . . . . . . . . . 70

C.4 Parameters - ellipsoid-approximated bone model . . . . . . . . . . . 73

C.5 Parameters - point-approximated bone model . . . . . . . . . . . . 73

$\begin{array}{ll}\text { Bibliography } & 75\end{array}$ 


\section{Notation}

In this thesis, general vectors are assumed to be decomposed in the target frame. For other decompositions, the notation ${ }_{i}^{k} \underline{r}_{j}$ is used, where $i$ denotes the frame with respect to which the motion is measured, $j$ the target frame and $k$ the frame of decomposition.

Furthermore, ${ }^{i} \mathbf{R}_{j}$ denotes the rotation matrix transforming coordinates with respect to frame $\mathcal{K}_{j}$ into coordinates with respect to frame $\mathcal{K}_{i}$. 


\section{Abstract}

The knowledge about skeletal kinematics is essential in many biomechanical and medical applications. However, an accurate, non-invasive and radiation-free method for bone motion tracking is still an open issue. This thesis addresses the development of a novel method for bone pose estimation that is both, non-invasive and accurate. The main principal is to palpate three prominent bone protuberances using pressure sensor planes attached to the skin. Bone protuberances are approximated by three ellipsoids that are rigidly attached together.

At first, the geometrical problem of the planar case is analyzed, where ellipsoids become ellipses and sensor planes become lines. After deriving the constraint equations describing the mathematical model of the system, Gröbner bases are used to find the number of possible solutions for two different numerically defined configurations of the lines and the ellipses. As a result, a maximum number of 32 different real solutions for the symmetrical and a maximum number of 64 different complex and real solutions for the general case are obtained. However, using the example of the symmetric case, it can be shown that the solution variety can be significantly reduced. From the 32 real solutions only three solutions are physically plausible, taking into account that pressure points are generated by an ellipse arc facing the lines.

This work also presents the general formulation of the constraint equations for the three dimensional case. As a solution approach, an optimization cost function is proposed including the squared minimal distances between sensors and ellipsoids allowing bone pose tracking that is insensitive toward input errors. Furthermore, a dual fluoroscopy validation of the method for three basic movements of the shank: flexion/extension, abduction/adduction and internal rotation is presented. It is shown that by pressure sensor palpation, bone tracking precisions of $0.5 \mathrm{~mm}$ to $1.0 \mathrm{~mm}$ and $0.3^{\circ}$ to $0.6^{\circ}$ can be attained with respect to dual fluoroscopy manual registration, thus, reaching the same order of magnitude as state of the art model based tracking techniques.

Finally, this thesis regards the limiting case where ellipsoids become points allowing the introduction of an automatable procedure approximating the rigid body bone geometry based on data from a previously performed bone pose measurement. Thereby, it is possible to fully circumvent radiation exposure that might be necessary to extract ellipsoid parameters from e. g. a computed tomography scan. Results indicate that deviations to the ellipsoid-approximated bone model are in the submillimeter range and may thus be negligible for many applications. 
